\title{
LA INTERACCIÓN GENERADA DENTRO DEL AULA BASADA EN LA OBRA DE AMPARO TUSÓN: ANÁLISIS DE LA CONVERSACIÓN
}

\section{GENERATED INTERACTION WITHIN THE CLASSROOM BASED ON THE WORK OF AMPARO TUSON: CONVERSATION}

\section{ANALYSIS}

\section{AUTOR/ES}

María Elena Del Valle de Villalba: Universidad Metropolitana (Caracas-Venezuela). manedelvalle@gmail.com

\section{CURRÍCULUM VITAE}

María Elena Del Valle de Villalba, nacida en Caracas, Venezuela, el 10 de marzo de 1970, graduada de Profesora en la Universidad Pedagógica Libertador en el año 1992, con especialización en Historia Económica y Social de Venezuela en la Universidad Santa María, con Maestría en Historia Económica y Social de Venezuela, tesis con mención publicación y suma cum laude, Doctora en Ciencias de la Educación en el Pedagógico de Caracas, Coordinadora del Núcleo de Investigaciones Ge históricas Lisandro Alvarado, cuenta con proyectos financiados por la UPEL y con participación de la Universidad Complutense de Madrid, con proyectos financiados por el FONACIT, investigadora certificada de la Universidad Complutense de Madrid, el grupo internacional CONCILIUM y del CELARG, ponente regular en eventos nacionales e internacionales, adscrita a la línea de investigación, Ciencias del lenguaje y con siete años de investigación en el área de análisis del discurso. Profesora Ordinaria de la Universidad Pedagógica Libertador. Investigadora acreditada del CYTED, la AECID y Universidad de Telemuco Chile. 


\title{
RESUMEN
}

El presente artículo presenta la propuesta de la investigadora para generar, basado en los aportes de Amparo Tusón específicamente, en su obra: Análisis de la Conversación (1997), un instrumento que permita describir las características discursivas y de la interacción que se generan dentro del aula en una clase determinada. El presente artículo se genera en el contexto de la realización de una tesis doctoral donde una de las categorías a definir es las características del discurso empleado por los docentes en el aula y la interacción que como consecuencia del mismo se genera con el estudiante en la enseñanza de la Historia Contemporánea de Venezuela. Para la descripción de la interacción se empleará como referencia el análisis del discurso oral y se usarán categorías definidas por Tusón (1998). Las categorías empleadas son: turnos de palabra, organización de la interacción, estilo de la interacción. Se anexa al artículo el instrumento diseñado por la investigadora quien parte para la realización de su tesis del paradigma cualitativo y el método socio-crítico.

PALABRAS CLAVE: Análisis del Discurso, Historia Contemporánea, Interacción

\begin{abstract}
This article presents the proposal for the researcher to generate, based on input from Amparo Tuson specifically in his work: Conversation Analysis (1997), a tool to describe the discourse and interaction that are generated within the classroom in a given class. This article is generated in the context of the completion of a doctoral thesis where one of the categories to define the characteristics of speech is used by teachers in the classroom and the interaction as a result of that is generated with the
\end{abstract}


student teaching Contemporary History of Venezuela. For the description of the interaction is used as the analysis of oral discourse and used categories defined by Tuson (1998). The categories used are: turn-taking, organization of interaction, interaction style. Attached to the article, the instrument designed by the researcher who starts to carry out his thesis the qualitative paradigm and the socio-critical method.

KEY WORDS: Discourse Analysis, Contemporary History, Interaction

\section{Análisis.}

La educación como práctica social tiene en principio algunas funciones. Socializar al individuo, dotarlo de las competencias básicas para insertarse de manera funcional dentro de una determinada sociedad, podríamos decir entonces que el estudiante es producto de la educación que recibe, es finalmente esa arcilla que el proceso pedagógico ha modelado. Etimológicamente, la palabra pedagogía deriva del griego paidos que significa niño y agein que significa guiar, conducir.

Se llama pedagogo a todo aquel que se encarga de instruir a los niños. Inicialmente en Roma y Grecia, se le llamó Pedagogo a aquellos que se encargaban de llevar a pacer a los animales, luego se le llamó así al que sacaba a pasear a los niños al campo y por ende se encargaba de educarlos.

El alumno es quien es guiada por el docente, llevado de la mano a configurar una cosmovisión específica, a través de sus enseñanzas recibe una descripción de la realidad. Dentro del aula es donde de manera convencional estos procesos se 
desarrollan. Dentro de ese espacio se establece un juego de roles en los que se asignan de manera consiente unas veces y otras no, papeles que tanto el alumno como el docente están llamados a desempeñar.

El docente a través de su práctica manifiesta y reproduce roles, construye un armazón que constituye en cada ocasión un hecho educativo y pedagógico con características concretas. Uno de los medios a través de los cuales se establece lo que podríamos denominar un estilo de pedagogía es a través del discurso verbal y no verbal que se usa dentro del aula. El discurso en este caso concreto marca los límites de las interacciones, las define, las estructura. Es a través del uso concreto que el docente hace del discurso verbal y no verbal que se establecen relaciones asimétricas $\mathrm{u}$ horizontales entre el docente y el estudiante.

En este campo de estudio específicamente, es donde la obra de Tusón (1997) tiene pertinencia. El análisis del discurso es el área donde su producción ha sido más abundante. Si bien es cierto que su objeto de estudio no es concretamente el discurso académico o aquel que se genera en espacios de aprendizaje, su obra suministra las categorías de análisis que permiten interpretar este discurso teniendo de antemano claro lo que se quiere observar y caracterizar.

Dentro de un aula de clases, al hablar el docente legitima, sanciona, pregunta, interrumpe, reprende, evalúa, en condiciones de cierta desventaja para el estudiante ya que es desde el vértice de su discurso que se constituyen los demás. ¿Cómo se define la interacción generada entre ambos? ¿Qué roles se asume que cada uno desempeñará? Son elementos que al analizar el discurso pedagógico de cualquier materia en concreto deben tomarse en consideración ya que pueden constituirse puertas abiertas o cerradas a aprendizajes que el estudiante debe experimentar. 
Nótese, que asumimos de antemano que en todo caso hay aprendizaje. Dentro de ese espacio académico el estudiante desarrolla su personalidad, sin calificar esta de ninguna manera. Se afianzan visiones del mundo o de una materia, las mismas pueden percibirse como aburridas, entretenidas, útiles, obligatorias y dentro de ellas el papel que debe jugar: repetidor, público, discípulo, etc. todo ello como producto del entramado que el docente construye a través de su discurso. De allí la importancia que tienen los juegos de poder y legitimación que se generan dentro del aula. La visión subjetiva que construye el estudiante es producto directo de esos discursos e interacciones que se hacen hábito dentro del aula.

En nuestro caso es la enseñanza de la Historia Contemporánea el espacio a estudiar. Son los discursos que se encapsulan en la práctica pedagógica: los del texto y los del docente que enseña Historia Contemporánea los que se busca caracterizar. La enseñanza de la Historia como ese lugar de encuentro en el que deben conformarse no solo competencias discursivas orales y escriturales, procesos mentales concretos, sino además ciudadanos venezolanos conocedores de su pasado, ciudadanos con mayúscula que son validados en su criticidad, respetados en la disidencia, es vital el encuentro polifónico y la promoción de actitudes constructivas.

Tusón (1997) establece las particularidades del discurso oral. Entre ellas: la imposibilidad de tachar y volver a empezar. La alternativa del docente en este caso en seguir hablando, de allí que los discursos estén teñidos de repeticiones, parafraseos y las florituras o limitaciones que tenga el docente en su esquema comunicacional. ¿Cómo habla el docente? de qué manera se establece esa metacomunicación tácita a través de gestos, tono de voz, entonación, caracterizando estos modos puede caracterizarse también el tipo de relación que se establece con el alumno. 
Gracias a la entonación se distingue la intención de cada oración: afectiva, instructiva, directivo, imperativo, motivador. Gracias al discurso gestual se establece el tenor del discurso: relajado, formal, frío, cercano, etc. Tusón (1997)y también definido por Searle (1980) con el mismo nombre, proponen también la distinción de lo paralingüístico, lo cual es definido como: la calidad de la voz, determinados estados físicos (afonía, dificultades respiratorias) el tono y el ritmo que describen estados de ánimo, emociones más o menos controladas, el énfasis que se hace en algún punto en concreto del tema desarrollado, recuérdese que los enunciados pueden ser dichos, murmurados, gritados, etc. y todo ello configura sin duda un discurso concreto.

A este respecto completa Tusón (1997) me refiero a esos ajá, mmm, eh, uf y otros, como chasquidos con la lengua, soplidos o aspiraciones (...) que son vocalizaciones que usamos para señalar extrañeza, asentimiento, duda e incredulidad p 23. Así mismo, la postura que se adopta al comunicarnos definidos por Searle (1980) como el factor Kinesico: sentados (al borde de la silla, con el cuerpo inclinado hacia atrás o hacia delante) de pie (apoyados en la pared, con las piernas separadas, con los brazos cruzados) paseando entre los estudiantes son todos factores importantes en la interacción que según la autora pueden ayudar a identificar una cierta actitud en quien la adopta, timidez, atrevimiento, soberbia, sumisión, agresividad, apertura, cerrazón, etc.

Dentro del aula, todos estos factores y específicamente en la enseñanza de la Historia pueden además de describir la interacción que se genera entre el estudiante y el docente, la concepción de la Historia y su enseñanza e incluso la corriente historiográfica a la que pertenece el profesor, dependiendo del énfasis que hace en diversos momentos o aspectos del contenido: discursos monológicos en el que el alumno solo escucha, fechas en la que se basa la narración de la Historia, procesos que son abordados legitimando o no diversas posturas, comentarios que se permiten, 
que se interrumpen, dinámicas de interacción que se permiten o prohíben de acuerdo con el hilo temático que se desarrolla.

Puede dentro del aula instaurarse o no una suerte de comunismo lingüístico definido así por Bourdieu $(1985,1991)$, en el que el discurso de poder del docente acapara los espacios de expresión. Tal vez el docente asume a priori unas competencias comunicativas en los estudiantes, tal vez dentro su discurso no se ha detenido a verificar que se esté hablando el mismo "lenguaje", tal vez ese docente no ha considerado que el estudiante puede manejar un dialecto deslegitimado en los espacios académicos y que al final de la clase termine él admirado de cuanto sabe su docente, pero sin aprender nada.

El docente tiene que estar consciente de estas asimetrías, asimetrías que el alumno quizás no le haga ver ya que al continuar sobre la marcha tal vez estas diferencias se oculten tras el artificio de una clase en silencio, pero la Historia como ciencia, la educación como proceso socializador no estarán cumpliendo con su papel. Las libertades que se otorgan dentro del aula, las preguntas que se hacen, la posibilidad o no de participar, las clases magistrales llenas de anécdotas, los estudiantes que escuchan sin emitir sonido pero no por ello, necesariamente aprendiendo.

El estilo de enseñanza del docente, su visión de la Historia, el culto a los héroes, el papel de los colectivos, las extrapolaciones al presente, la vigencia de los contenidos que se desarrollan puede identificarse a través de esos indicadores. Otro aspecto a observar es lo que Tusón (1997) denomina los turnos de palabra, definido como la alternancia de turnos, sucesión de intervenciones a cargo de diferentes hablantes. ¿Existe en la clase un sistema de turnos? ¿quién los determina? ¿los turnos tienen una duración determinada? ¿quién participa más? ¿existen algún tipo de censura? ¿cómo maneja el docente la disidencia? ¿Tiene la clase una estructura rígida? ¿Existe 
conversación o es más bien un monólogo donde el docente habla muchas veces con un lenguaje que solo él comprende?

A este respecto agrega Tusón (1997) Los profesores explican aconsejan, preguntan riñen, animan, a los estudiantes quienes a su vez contestan, preguntan lo que no entienden, se rebelan, etc. todo esto, agrego si se les permite p 91. Un profesor continua, puede comportarse como un tirano, dictando la lección y dando órdenes, sin dejar espacio para que los estudiantes participen, o puede actuar como una persona abierta al diálogo, que estimula y motiva a sus estudiantes para que vayan construyendo de forma activa sus conocimientos y matizando sus actitudes p 91.

Lo buscamos es hacer etnografía de la comunicación, describir, entender y explicar cómo funcionan las diferentes colectividades humanas, en este caso la concentrada en el aula de clases, a partir de la observación de sus comportamientos comunicativos. Los comportamientos comunicativos dentro del aula pueden además ser descritos atendiendo a una serie de componentes identificados por Tusón (1997) como:

- Situación.

- Participantes.

- Finalidades.

- Secuencia de actos.

- Clave.

- Instrumentos.

- Normas y

- Género p 74.

La Situación es definida en un doble sentido. Primero como el lugar, la localización espacial y temporal en que se produce el encuentro comunicativo. En este caso es el 
aula esa situación, la mesa del profesor y las mesas de los estudiantes. Así mismo está constituido por fronteras internas que pueden estar definidas por sub-eventos comunicativos incrustados en el interior del acontecimiento global, que este caso puede ser una sesión de trabajo en grupos, la puesta en común, los períodos dedicados a aclarar dudas, etc. En segundo término, la situación se refiere también a la atmósfera psico-social. En el caso de un aula, esta situación es configurada en función de las actitudes que se generan en el aula.

Los Participantes son las personas que intervienen en la interacción. ¿Cuáles sus características psicosociales? Edad, sexo, clase, identidad étnica, estatus, papeles, repertorio verbal, bagaje de conocimientos, etc. p 76. Todos estos elementos en una clase de Historia pueden desencadenar procesos en cada participante dependiendo del tema desarrollado y de la postura ideológica de cada uno. Si se desarrolla un tema que despierta o lastima susceptibilidades en concreto como lo puede ser, lo racial, las desigualdades económicas, tendencias partidistas, todos estos elementos juegan un papel predominante.

Las finalidades se refieren a los objetivos que se persigue con la interacción, los productos que de ella espera obtenerse. En nuestro estudio, la finalidad es social, institucional, académica, la formación de un estudiante con un perfil en concreto, algo que podríamos denominar como un alumno estándar con competencias escriturales, discursivas y cognitivas específicas. Alguien que sepa quién libertó Venezuela, quien descubrió América, qué ocurrió el 12 de octubre, que no interrumpa a los mayores, que no hable con la boca llena, que no levante la voz, que no hable si no le preguntan que para intervenir levante la mano, que pida las cosas por favor es decir, un estudiante "educado". 
Las secuencias de actos: se refieren a cómo se estructura y se organiza lo que se va diciendo en la interacción, relacionado con los turnos de habla ya explicados en líneas previas p 77.

La Clave: se refiere al grado de formalidad/informalidad de la interacción, es decir, al tono (serio/lúdico, consensual/conflictivo, íntimo/distante, etc.) que en cualquier caso sirven de indicadores del grado de formalidad de una interacción p 78.

Los instrumentos: incluyen: 1) el canal, es decir, el medio a través del cual circula el mensaje; en nuestro caso es la comunicación cara a cara. 2) Las formas de hablar, aquella parte del repertorio verbal y se activa en este concreto intercambio. 3) Todos los elementos cinéticos y proxémicos (gestos, posiciones de los cuerpos) también descritos previamente $\mathrm{p} 78$.

Las normas que son de interacción. Las de interacción regulan quienes participan y cuando, así como la manera en que lo hacen, si se puede interrumpir o no, si hay que esperar a que le profesor pregunte o puede participarse libremente. Y por último el género el cual define el tipo de hecho comunicativo: conversación espontánea, debate, etc.

Finalmente, es necesario asumir que el aula de clases no es una comunidad de habla con entidad homogénea y que además de las barreras que el uso del lenguaje puede levantar entre el docente, el saber y el alumno, si queremos lograr aprendizaje significativo la dinámica comunicacional debe ser observada y evaluada cíclicamente en busca de buenos resultados.

La obra de Amparo Tusón, permite a partir de la base de sus referentes teóricos, aproximarnos a la observación de la dinámica generada dentro de un salón de clases 
teniendo claro los aspectos a observar. De allí se generarán las categorías emergentes en cada dinámica comunicacional, permitiendo de esta forma caracterizar el uso del lenguaje verbal y no verbal, la interacción entre estudiantes y profesores y el hecho pedagógico específico que resulta como consecuencia de los mismos.

La recomendación para quien desee hacer estudios similares es que la observación de la dinámica de clases debe hacerse a través de la grabación de videos en diferentes momentos. En videos, porque dada la velocidad en la que a veces las interacciones se generan, el video permitirá detenerse de manera más acuciosa en los detalles, tanto verbales como no verbales $\mathrm{y}$ en diferentes momentos, porque no todas las actividades desarrolladas dentro del aula son las más idóneas para develar la dinámica de las interacciones.

Sin duda, la obra de Tusón (1997) será de gran utilidad para realizar la observación estructurada de las clases y caracterizar los elementos presentes en las mismas.

\section{Bibliografía.}

BOURDIEU, P. (1985) ¿Qué significa hablar?, Madrid, Akal.

BOURDIEU, P. (1991) El sentido de la práctica, Madrid, Taurus.

SEARLE, J. (1980) Indirect Speech Acts, en P. Cole y J. L. Morgan (eds). Syntax and Semantics, 3: Speech Acts, Nueva York, Academics Press.

TUSÓN, A. (1997) Análisis de la Conversación. Ariel Practicum. Barcelona. España. 